\title{
Learners' Dialogical Interaction in the Service of Linguistic Knowledge Acquisition in Group Settings: Based on Contextual Factors
}

\author{
Huanjie Wang \\ Ningbo Wu Xiang High School, University Nottingham, Ningbo, China
}

\begin{abstract}
This paper highlights some connections between dialogical interaction and knowledge acquisition in group settings. In learners' quest to develop communicative competence and self-identity or social identity and acquire knowledge, dialogical interaction is applied to three contexts of knowledge-acquiring process where learners' identity, learners' mindset, learners' rapport, learners' communicative competence and learners' knowledge are involved. Simply speaking, learners in collaborative contexts tend to share existing knowledge to generate potential knowledge; learners in competitive contexts are inclined to build knowledge, learners in cohesive contexts just use knowledge as a tool to organize knowledge. However, it is contended that dialogues are supposed to be explicitly regarded as part of the knowledge-acquiring process. There is a tendency to enable more effective knowledge acquisition through communicative talk, especially dialogues, in the interactive contexts with scaffoldings, tutoring or even intervention.
\end{abstract}

Index Terms - dialogical interaction, knowledge acquisition, communicative competence, self-identity, socialidentity, intervention, context, group

\section{INTRODUCTION}

With the intention of understanding the relationship between learners' dialogues and knowledge acquisition I propose to refer to the contextual factors of interactive dialogues in group settings, where knowledge acquisition cannot succeed without an individual's effort and group work. Student Team Learning (STL) originally developed by Robert Slavin (1980, 1989/1990, 1995) emphasizes individual accountability, team goals and team success. The Jigsaw technique (Aronson and Yates, 1983; Aronson and Thibodeau, 1992; Aronson and Patnoe, 1997) emphasizes group cooperation and individual accountability. From research results, it is found that academic performances and active interactions lead each learner in an essential role as contributor to the achievement of their common goal in groups. In addition, Group work and cooperation need talk which plays a vital role in knowledge acquisition. As knowledge-building discourse (Chuy et al., 2011) indicates, talk or dialogues can promote construction of knowledge in some way. Singh and Mohammed (2012) also argue that knowledge construction occurs when learners participate in the negotiation of meaning. Indeed, dialogue help learners understand and have access to the self, and more importantly to knowledge acquisition in groups.

In fact, many items of research focus on dialogues in the cooperative context, thus ignoring the contexts where learners debate with each other, voice their opinions in a neutral way, or just use talk as a tool to organize tasks and activities. However, it seems somewhat paradoxical that dual emphasis is put on both cooperative and conflicting contexts and we should bear in mind that interaction is dynamic, moving through different "modes". Members in groups sometimes participate in discussions politely while sometimes conflicts or debates may arise. Dialogic modes of interaction may be reached by groups with a high motivation to reflect and generate shared insights (Scharmer, 2009).

A dialogical interaction mechanism in different contexts has been not fully established in the group setting and does not make differences to knowledge acquisition. In order to stress modes of knowledge construction and acquisition, argumentation strategies and discourse in schools have often been researched (Pontecorvo \& Sterponi, 2002; Alexander, 2004), apart from means to form and participate in contexts (Wertsch, 1991; Hicks, 1996). It is noted that learners' talk in the group is not only a means of understanding what learners reflect on, but also a way of forming and expressing what they think in order to acquire knowledge. Similarly, the trajectory of a learner's participation within a specific context of dialogical interaction has been observed by some researchers (e.g, Bruner, 1996; Wenger, 1998). Thus, this paper is really intended to deal with knotty situations or contexts where knowledge can be well acquired and constructed through constructive or productive dialogues in groups.

In groups, learners may not know who they are or their perceptions of themselves in dialogical interaction: students' incomprehension of themselves as learners (Hood, 2007) does not help manage their process of knowledge acquisition. Instead, learners' identity plays a meaningful and significant role, which makes learners' knowledge acquisition more conscious and solution-oriented.

Is it learners' differences that make dialogues interactive or prevent them from being interactive? In group settings, the phenomenon of unequal attention and opportunities distributed among learners' dialogues is objectively prevalent 
due to some learners' prompt responses and outstanding performances based on subjective reasons such as their being more brave characters or having stronger motivation, as well as other objective reasons. On one hand, the seating arrangement of learners in groups largely neglects learners' potential in the support of learning (Blatchford et al., 2003) and the learners' differences in nature. On the other hand, the group setting that is in a relatively independent but open environment, however, is subject to excessive interference or insufficient support. For example, unnecessary directive commands from teacher lead to "rigid" and "passive" dialogical behaviors among group members. In many cases, some of the students lose enthusiasm for communication with others if they do not expect timely evaluative feedback and scaffolding.

When it comes to learners' mindset in groups, importantly though, periods of calm and collected engagement may alternate with stages of conflict and instability in the dialogic interaction as a learning system (Hurst, 1995). That means learners' mindset is dynamic. Chen Xiangming (2003) argues that the participants' psychological feelings such as security, trust, and interdependence are needed to learn in group cooperative learning. These feelings are of great necessity in cooperation but may be still or even more necessary in competition or in dialogical cohesion. In point of fact, competitive interaction and cohesive interaction in the group setting are common. Therefore, the feeling of calmness in the face of disagreement, patience in stagnation of dialogic interaction, independence in deviation and interference, emotional uncertainty and flexibility in dealing with generative knowledge should be taken into consideration by learners especially in competitive cases and in "information exchange" deviation, or just in instrumentally cohesive contexts, to ensure a smooth dialogue and in turn to acquire knowledge. In addition, corresponding to and underlying the distinctive characteristics of learners' behavior in groups, the group has a specific psychological process: "self-grouping" process or a self-categorization (Turner, 1985), which may help learners build a sense of belonging in an organization. Therefore, teachers should expect that students in the group activities may have the experience of tension, so the student's "psychological flexibility" is supposed to be paid attention to by teachers or tutors and they may make the appropriate adjustments (Ren, Tim, 2013).

Apart from these necessary feelings, learners have not been able to talk and listen with dialogic strategies, which actively engage learners in reciprocal, conversational exchanges with participants. Unfortunately, in Wu Xiang High School, a considerable proportion of students cannot listen well to others' perspectives and share ideas with each other. However, listening to alternative views and sharing ideas with each other should be incorporated in interaction (Lennox, Sandra, 2013). Besides, dialogues occur in every interactive occasion and link; they play an instrumentally organizational role as well as a wisdom blend in communicative learning. All groups need to strike a balance between task and maintenance; between teachers' and students' conversations, and between questions and answers; these balances will change (Seng \& Liu, 2005). Therefore, face-to-face promotive interaction (Ma Hongliang, 2003) or constructive interaction is conditioned by necessary scaffoldings or timely intervention in some way. During scaffolding or even intervention, the most intensive interaction takes place (Chi et al., 2001). However, there may exist too much or too little scaffolding or intervention in implicit intergroup or extra-group conflicts, which more or less hinder information transfer and transmission.

As for learners' rapport, unfortunately, good group membership formed in dialogues to promote knowledge acquisition is not well dealt with and focused on by researchers. Their affiliations in dialogical interaction in different contexts are exposed to challenges or conflicts in knowledge acquisition. Generally, group membership is related with in-group favoritism (positive or friendly attitudes towards members in groups) and extra-group derogation (negative or unfriendly attitudes towards those outside the groups) (Simon, 1992). Besides, through language use, group boundaries have been created and reinforced by means of communication (Apker et al., 2004; Bleakley, 2006) and how information is received and transmitted is also affected by social identity and learners' relationships. Learners' rapport is derived from the greater valuing of sources shared in groups (Wilder, 1990) and more joint efforts to recall information which may be encoded (stored) differently from in-group to extra-group members (Ostrom et al., 1993). In the face of these, particular attention should be given by teachers or tutors to facilitating interactive interrelationship among group members, as well as their self and social identity to establish their rapport in dialogues.

More importantly, learners' knowledge acquisition sometimes stays at the shallowest levels through dialogues in groups if there is no sense in dialogic contexts at all, or inadequate interaction in dialogic groups. Apart from this, learners do not use talk as a means to acquire knowledge. For example, in traditional classes or extra-curricular classes in Wu Xiang High School, learners gain knowledge in a monotonous and mechanical way: "recitation, transcription, mechanical repetition and monologue" account for a considerable proportion of knowledge-building. To some extent, the acquisition of knowledge mostly stays at the level of declarative knowledge acquisition in dialogic groups, ignoring procedural knowledge and strategic knowledge (Lu Hai Dong, 2005). The latter two in the long run affect learners' ability to acquire new knowledge, to create knowledge and use knowledge in dialogic groups. Specifically, knowledge should be re-constituted and re-created through dynamic, interactive activities" (Swan, Newell, Scarebrough \& Hislop, 1999 ) in dialogic groups. In brief, knowledge acquisition does not rise to the process of knowledge transformation but to that of knowledge transfer in dialogues among group learners. What is worse, knowledge acquisition in different dialogical contexts is not seriously taken into consideration by researchers. Actually, knowledge acquisition can be effectively internalized and transformed through socially open communication and contextual application in groups based on particular contexts. 
How well the interaction is carried out in a particular dialogue context has recently been increasingly researched (e.g, Murrary \& VanLehn, 2006; M.Chi, VanLehn, Litman, \& Jordan, 2010, 2011a, 2011b). However, the profusion of pieces of research conducted in the past or relatively recent years on dialogical interaction showed it is neither how communicative talk helps learner acquire knowledge that is valued, nor the dialogical "modes" in the different contexts --- for example, how learners in collaborative contexts tend to share existing knowledge to generate potential knowledge; how learners in competitive contexts are inclined to build knowledge; how learners in cohesive contexts just use knowledge as a tool to organize knowledge. So this paper intends to deal with operations in three dialogical contexts where learners collaborate with each other, compete with each other and promote organizational and linguistic cohesion through dialogues aimed at the improvement of knowledge acquisition.

\section{LITERATURE REVIEW}

\section{A. Knowledge Acquisition}

What is knowledge Acquisition?

Basically, Lethbridge (1991) defines knowledge acquisition as a recursive process where the concept's level of formality can be improved by achieving the formality of connected concepts and providing the interpretability of the concept's uninterpreted content. A working definition of knowledge acquisition was developed by the researcher Chivonne Algeo (2014) as: "knowledge acquisition for an individual takes place when information broadly, or ideas from other people, are accessed, processed, captured, and retained, adding to that individual's tacit knowledge". From its definition, knowledge acquisition is the process of accessing and absorbing knowledge not only from teachers but also from other sources and resources under more comprehensive circumstances. Generally speaking, knowledge acquisition is described as the natural process of extracting, structuring, and organizing knowledge through direct or indirect contact or interaction with a knowledge source.

\section{Differences between Knowledge Acquisition \& Learning}

The difference between "acquisition" and "learning" is questioned by Munsell and Carr (1981). Learning is one means of knowledge acquisition. Knowledge acquisition, although non-linear and haphazard, is not a random process (Inkpen, 1998) while learning is a conscious process serving as "monitor" of performance only under certain conditions. Learning takes place when the range of potential behaviors increases with the knowledge processed (Huber, 1991). According to Lujan and Dicarlo (2006), learning is the capacity to take advantage of resources to explore, make evaluations, and apply information, not just memorizing a set of facts. For example, knowledge acquisition is not usually confined to happening in organized group dialogical activities in class but in daily dialogues or in after-class dialogues, while learning formally occurs in the dialogical context under teachers' or tutors' instruction or from all sorts of experiences in activities. So learning is fundamentally affected by the activity and context where it is embedded (Brown, Collins and Duguid, 1989).

\section{B. Dialogical Interaction}

\section{Definition of dialogical interaction}

Dialogue is a form of conversation or talk where self-identity and social identity in knowledge acquisition are both conveyed in words through shared ideas. Some researchers see it as a balanced process where innovative knowledge is generated. Martin (2005) argues that it stimulates new understanding, insight and action. Besides, dialogue is frequently treated as a way of encouraging collaboration, developing awareness and promoting collective action (Heymann and Wals, 2002; Roper et al., 2004), causing some collective and individual shifts in learners' behavior, mindset and organization.

There are many kinds or forms of dialogues with different uses and functions. Wegerif and Mercer (2000) have defined three kinds of talk as follows: a) Cumulative talk: speakers' talk based on what the other has said uncritically, but positively features repetitions, elaborations and confirmations. b) Disputational talk: featured by disagreements and individualized short assertions, and decision-making and counter-assertions. c) Exploratory talk: participants engage with each other's ideas critically but constructively, providing alternative hypotheses as well as justifications. Reasoning in the talk is more visible and knowledge is made publicly explicable, and progress results from the final agreements reached. Disputational talk is suitable for competitive contexts, cumulative talk is fit for cohesive contexts and exploratory talk caters to blended contexts both in the collaborative and competitive one.

In the classroom context, the concept "dialogical interactions" is defined by Alexander (2008) as exchanges where learners raise questions, explain their viewpoints and make comments on others' ideas. In dialogues, learners make an interactive effort to generate understandings and new insights together through a balanced process of reflection, advocacy and inquiry (Bronn and Bronn, 2003).

The concept of dialogue interaction has occupied an important position in the areas of transformative and social learning for a long time (Arjen et al., 2012). Dialogical interaction serves as one principle for knowledge-construction within the Community of Learners (Koschmann, 1999). The dialogical theory (e.g. Grossen 2010)'s emphasis on interaction is similar to the focus on knowledge-acquisitive interaction. An atmosphere of mutual trust, respect and cooperation is needed in this process of dialogic interaction (Van Gorder, 2007) where dialogue works as a way for promoting students' participation, independence, confidence and responsibility in learning (Alexander, 2006). 
Importantly, in dialogic interaction group members should show a variety of opinions on the collective task; their own and each other's perspectives and assumptions must be critically examined by participants (Gunnlaugson, 2007).

\section{Learner's self-identity and communicative-competence in dialogical interaction}

\section{a. Self-identity \& social identity}

Gee (1999) recognizes identity as a certain kind of person through discourses, or combinations of ways of acting, thinking and interacting. Having a better understanding of the interface between identity and ideology (ideas held by a particular group or person) (Van Dijk, 1998) will make a difference to knowledge acquisition. Learner's identity involves self-identity and social identity.

Self-identity refers to the individual in the "the fullness of being" which involves physical, spiritual, affective and thinking self (Yorks and Kasl, 2006). Self-identity helps "connect our inner visceral and somatic experience to our being-in-the-world" (Kepner, 2003). Understanding and knowing are associated intimately with the building of identity and closely based on language or communicative activities (Talja et al., 2005). A dialogue in an instructional context is intended to construct a new sense of what is the self and what is experienced, or through dialogue identity is conceptualized and built. In dialogues, identity development and knowledge-building processes are to track down in interaction (Liorio, 2010). Richard Bauman (2000:1) defines individual (self) identity as being constructed from a "socially constituted repertoires of identificational and affiliational resources and craft these semiotic resources into identity claims for presentation to others".

Ochs (1996:424) defines social identity, which involves learner' roles, relationships, reputations, positions, and other dimension of social personae, which are conventionally connected with cognitive and emotional stances. Learning selves are dialogically established across 'trajectories of participation' (Greeno, 1997). Situated in different practices, learners do not only approach the dialogical relationship that takes place "in the realm between one person and another provided both are open to it " (Hycner, 1993) with other persons, but also with the whole sociocultural environment where the interactional situations occur (Linell, 2009). Based on this point, social identity generically refers to an individual's self-concept in relation to his or her membership of social groups (Brewer, 2001) and it exists at both group and individual level simultaneously and bridges the gap between them (Postmes et al., 2010).

Drawing on Social Identity Theory (Taifel and Turner, 1979), Ellemers and Haslam (2012) note that social identity underpins intergroup behavior and interpersonal behavior. Learner's responses are understood in terms of subjective beliefs about different groups and relations between them, instead of instrumental concerns and material interdependencies, objective individual and group characteristics, or individual difference variables. Social Identity Theory assumes that interactions between learners are primarily formed by their group affiliations to which learners perceive themselves as belonging.

\section{b. Communicative-competence}

The notion of communicative competence was presented by a sociolinguist (Hymes, 1971) to encompass the appropriateness of an utterance, or knowledge of sociolinguistic rules, as well as knowledge of grammar rules. Communicative competence builds on a negotiation of meaning between speaker and listener, interviewer and interviewee, tutor and tutee. In language teaching contexts, the notion has been used to refer to the ability to negotiate meaning to successfully combine sociolinguistic, a knowledge of linguistic, and discourse rules in communicative interaction (Savignon, 1983).

Knowledge acquisition is strongly associated with communicative competence and participation of learners in the interactive and dynamic process of communicative talk. Knowledge arises from communication rather than information (Tuominen et al., 2003; Schreiber, 2004). Communicative competence is based on adequacy of communication, functionality of communication, and sufficiency of knowledge, skill and judgement (Baker and MacIntyre,2000; Yashima et al., 2004). Savignon (1983:9) argues that "communicative competence is relative, not absolute, and is determined by the cooperation of all the participants involved." It should be pointed out that communicative competence also importantly relies on the competition and cohesion of all the learners involved.

\section{c. Current studies on dialogical interaction: Difficulties and possibilities}

Although there now exists a growing number of pieces of research that have studied various dialogical modes and their use or functions in general, no study could be found that has revealed the connection between dialogical interaction and knowledge acquisition in the group settings and specific operation of dialogical interaction in particular contexts. This research, then, aims to identify contextual factors on which constructive or productive dialogical interactions, well established or organized, are based, problems and challenges emerging among member's dialogues in groups that are associated with their identity, mindset, rapport, communicative competence and knowledge and so on. Thus, we intend to discover the contextual influence on dialogical interactions in groups and specific operations in them.

\section{Contextual Factors}

\section{What does context refer to?}

Three significant factors in groups - learner features, organizational features and task features - affect the achievement of learning transfer (Barnett, 2005). While in dialogical interaction, learners should keep some factors in their mind to make dialogues smooth and meaningful, such as learners' identity, mindset, rapport, communicative competence and knowledge, as well as learners' intention, feelings, tasks, conditions, dialogical organization and so on.

2. Factors: psychologically collaborative context, formally competitive context, instrumentally cohesive context 
Learners' neutral stance does not actually exist in dialogical interaction; they tend to be collaborative, competitive or cohesive (dialogues as instrumental or organizational links).

\section{1) Psychologically collaborative context}

A collaborative context is based on consensus reached through working together or cooperative work or activity by group members, in contrast to a competitive context, where individuals attempt to outdo other group members. Whether the dialogue is advancing to a knowledge objective is a key problem in collaborative knowledge-creating/knowledgebuilding discourse (Bereiter et al., 1997). Collaboration is a philosophy of interaction where individuals take responsibility for their actions, including learning and respecting the contribution and abilities of their peers (Marjan, 2013). Learners cooperate with others to increase information sharing, resolving conflicts, managing the group interaction process, reaching agreements, as well as reducing ambiguity and hostility among members. In this context, dialogical interaction is operated as the following sequence: plan-making, knowledge extraction and analysis, meaning negotiation, decision making and verification. The interaction process induced by this context produces a number of noticeable advantages: stimulations are more likely to be offered in a secure setting where members are encouraged to speak out in the face of knotty problems. Besides, maximal influence is exerted on learners' rapport in group interaction.

\section{2) Formally competitive context}

Wilhelmson (2006) argues that if the disruptions and conflicts contribute to learners shifting, broadening or transcending their perspectives, those situations that likely appear from learners' different perspectives can actually be vital to provoke transformative insights (Wals et al., 2009). That is, a competitive context contributes to the effectiveness and efficiency of knowledge acquisition through contested voices. Debate and argumentation are specific forms in such contexts. The organization of knowledge can be considerably improved by the distinctive structure of argumentation, which connects conditions, premises, rebuttals, conclusions, and so forth (Billig, 1996; Kuhn, 1992; Merns \& Voss, 1996). Drawing on such a competitive context generally as a tool for personal improvement (Edwards, 2008), critical thinking and the capacity to deal with problems in heterogeneous groups are underscored.

\section{3) Instrumentally cohesive context.}

Communication disorder occurs through weak ties, going beyond the boundaries of cohesive groups or even when linguistic cohesion and organizational cohesion are at a premium. Can groups be systematically and efficiently addressing issues in dialogical and organizational disorder? To assure knowledge acquisition continuity, communicative obstacles or misunderstandings which arise from inconsistent ideas, ambiguities and conflicts in dialogical interaction should be removed. Instead, strong ties among members should be built through talking. That is, linguistic cohesion serves a premise of organizational cohesion: both are beneficial to the communication of cohesion. Coherence and cohesion in language use are expected to be achieved; at times communicative links such as scaffolded dialogues (Alexander, 2001) can achieve consensus through sequenced and structured questioning, and through 'shared conception and joint activity', which prompt, guide, reduce choices and accelerate 'handover' of principles and concepts. Tutoring as a potential outcome in instrumental settings in transformative learning (Mezirow's, 2000) is hopefully provided and thus conflicts can be well dealt with.

\section{Relations between those contexts}

The importance of the relationship between collaborative, competitive and cohesive contexts (Figure 1:3-C contexts) is appreciated due to the intersection and interaction among them. In the loci of intersection, scaffolding or scaffolded dialogues should all be provided in three contexts where dialogical interaction featuring emotional and ideological dynamic process needs some instrumental support or directive help from others, such as intervention or tutoring if necessary. Differences in these factors depend on learners' characteristics of dialogical interaction in knowledge acquisition in the following aspects: learners' identity, learner's mindset, learners' rapport, learners' communicative competence and learners' knowledge. Specifically speaking, learners in collaborative contexts tend to share existing knowledge to generate potential knowledge; learners in competitive contexts are inclined to build knowledge; learners in cohesive contexts just use knowledge as a tool to organize knowledge.

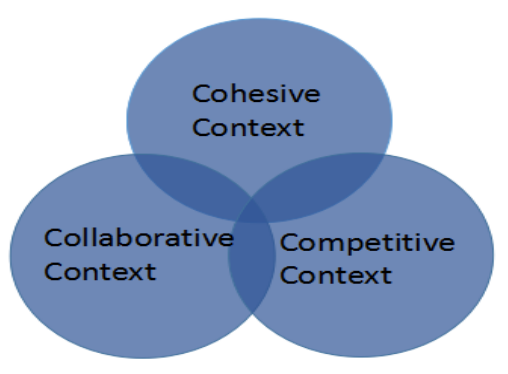

Figure 1: 3-C contexts

To sum up, the intimacy and involvement of learners in dialogue contribute to the efficiency of knowledge 
acquisition. Vitality of each context exists in spite of intervention from others and uncertainty in dialogues.

\section{Methodology}

My research uses the interpretive or constructivist paradigm. Ontologically, students' voices as a knowledge reservoir have not fully been exploited by researchers. This kind of knowledge consists of contextual knowledge, my practitioner knowledge, students voices valued, their experience and practice in class through analytic generalization. Dialogues can promote development of children's thinking (Mercer \& Littleton, 2007).However, not all voices from students can produce new knowledge. Actually, it depends on the use of voices in interaction. What's more, the reality of DI in service of KA is created by students in groups. Epistemologically, the underlying meaning of students' DI in different contexts is discovered with qualitative methods such as interview, observation, recording and so on with methodology of action research improving.

As the systematic inquiry (Mills, 2003), AR is adopted to picture the authentic DI scenes in the groups and develop understanding of the process of DI, and it emphasizes on producing new knowledge, as Dewar and Sharp (2006: 221) state that action research emphasizes the production of knowledge and action directly useful to practice and the empowerment of people, at a deeper level, through the process of constructing and using their own knowledge. Action research is thus deliberately concerned with the processes of development, improvement, and continuous learning.

The method of observation is used to enable me to look afresh at students DI performance in the groups learning that might be taken for granted, expected or go unnoticed (Cooper \& Schindler, 2001: 374). I use observations as means of data accumulation to find the nature and regularities of the DI. Observation yields the authentic data systematically but also its sensitivity to contexts and strong ecological validity (Moyles, 2002), because it provides a reality check (Robson, 2002: 310).

It should be still noticed that dynamic nature and flexibility of observational data collection (Simpson \& Tuson, 2003: 17) make it hard to record systematically all the data I really need. Particular attention is paid here to the use of videorecording as a method to capture the fullest-possible range of performances and interactions in three separate contexts. Field note is another useful tool to record what I hear and observe. Russell and Gery (2010) stress that field notes are "an essential part of all qualitative data collection... Producing field notes is a process of identifying themes" (Russell \& Gery, 2010, p.46). In the field note, I can make comprehensible account of the process of students' DI performances and even reconstruct the dialogical conversation, from which I give pen portraits of the relationships between studen ts' words and minds.

The method of verbatim transcribing is adopted in turning voices into written words. When having the voices transcribed, I note not only the literal statements of DI but also their non-verbal and paralinguistic communication. The original data should be kept intact without any manipulation or transformation. As a "co-produced text" (Riach, 2009), a transcript is an interpretation (Mishler, 1991) that is constructed as a new, original text by the researcher (Denzin, 1995). However, transcriptions inevitably lose data from the original encounter because of translations from oral regulations to written rules.

Because of group settings, I use the method of group interviewing to collect data for several reasons. Firstly, a group of students are interviewed for a common purpose in the group interviewing where students are aware of what other students in the group are saying (Watts \& Ebbutt, 1987), thus it can generate a wider range of responses. Secondly, group interviewing can yield "a cross-check" effect (Arksey \& Knight, 1999: 76) which means students can complement the other with supplementary ideas, resulting in a more reliable and complete data. Thirdly, it helps construct the group knowledge produced in the students' DI trajectory through "group voices", discouraging individual voice. As a whole, there are practical and organizational advantages. However, all students should be given chances to voice their ideas. I should be prepared to deal with the students who are marginalized or monopolize the conversation.

\section{RESULTS AND ANALYSIS}

In some way, different contexts have its uniqueness to facilitate students to acquire knowledge. Learners are expected to establish a contextual foundation of their talk, and also need talk to build that contextual foundation. DI can work as facilitator to acquire knowledge in different contexts where the voices play a role as transmission as well as transformation of knowledge.

In the collaborative context, by pooling and sharing resources, an individual resource can internalize dialogue' content and transform different resources into their own. There are indications that learners can collectively reflect on the language use and interactive efficiency through collaborative dialogues. In addition, the result indicates that collaborative context increase more learners' interaction and dialogue, engagement.

Different from collaborative context, argumentative context has its charm in dealing with disagreements face to face. Because of communication in the dynamic for change, disagreement can advance students' knowledge building. On the other hand, the study shows that argumentative reasons cultivated in such a context develop students' cognitive competence (Kuhn \& Udell, 2003). Another difference is that rather than unquestioningly accept others' certainties, students learn to test evidence, analyze idea and explore values.

In the cohesive context, speakers can make inter-textual links in their joint meaning-making because talk can 
function as knowledge "connection building" (Gee \& Green, 1998). It must therefore be recognized that misunderstandings are likely to arise and the thread of a developing understanding may be broken if there is no cohesive context and continuity through dialogues.

From linguistic and inter-mental to organizational dimension, there have been changes across different implications that have combined to create the dialgoical engagement of inter-connectedeness between individuals in an organizational setting. Learners are capable of getting the best out of all groups members' thinking as well as their own thinking (Grugeon et al., 2001, p. 95).

\section{DisCUSSIONS}

\section{A. Can Dialogical Interaction Really Serve Knowledge Acquisition?}

Not all kinds of dialogical interaction make sense in knowledge acquisition. Dillenbourg (2002) emphasizes particularly the danger of disturbing "natural" interaction and "natural" problem-solving process, and the danger of artificially "didactising" interaction. Constructive dialogue's significance is also explicitly acknowledged in organizational knowledge creation (Tsoukas 2009; Won Krogh et al., 2000), which has the same basic concept as Knowledge Building (Bereiter \& Scardamalia, 2014), where context and interaction are pivotal concepts in the study of all kinds of meaning-making process, such as cognition, communication, and language (Linell, 1998, 2009). In collaborative contexts, learners' tension and independence in dialogical interaction are needed while their calmness and dependence are necessary in competitive contexts, which is not a paradox. The reasons lie in potential outcomes that the complementary balance between learners' behaviors and emotional tendency will produce in knowledge acquisition. Apparently, productive or constructive dialogical interaction in cohesive contexts at least staves off the state of ambiguity, lack of continuity or inability to proceed further in the knowledge-acquiring process.

\section{B. Discussion on How Learners Interact through Dialogues in Group Settings Work based on Different Contextual Factors. What Matters Should Be Taken into Consideration}

Co-regulation of group members is required in dynamic dialogues. Salonen, Vauras and Efklides (2005) argue that the co-regulation of interpersonal relationships and (each) cognitive information will help form group dynamics to solve problems. In addition, co-regulation in some degree promotes good relationships in groups. Group members' rapport is the basis on which constructive dialogues are formed. As a consequence, classroom interaction has been shifted away from traditional practices/transmission (Blatchford et al., 2006) because of the supportive classroom/teaching activity and mutual/interpersonal communication where effective group working will be based on positive within-group relationships. Learners' joy and sense of accomplishment from experiencing accumulation of dialogues and tacit knowledge in turn consolidate and stabilize this good relationship; on the contrary, hatred, arrogance and inner resistance in communication do harm to it. Besides, Attention and opportunity distribution in dialogues may influence relationship among members through seating arrangements and interactive inclination.

Learners' identity, mindset and rapport vary in different contexts (see Table 1). Scaffolding and tutoring play a vital part in the interruption and stagnation in dialogic integration. The time when they are offered differs (see Table 1). Several researchers have proposed that tutoring has its highly interactive nature---the large extent to which the tutor and student make response to each other and base their next contribution on each other's dialogue moves (e.g, Graesser et al., 1995; Chi et al., 2001; van de Sande \& Greeno, 2010). At last, interactive intervention and dialogical skills or strategies are also necessary in different contexts (see Table 1). Learners learn to share, contest, organize knowledge in different contexts to acquire new knowledge (see Table 1).

TABLE 1

MATTERS CONCERNED IN 3-C CONTEXTS

\begin{tabular}{|l|l|l|l|}
\hline Learners & In collaborative context & In competitive context & In cohesive context \\
\hline Identity & Cooperator & Competitor & Organizer \\
\hline Mindset & Tension /independence & Open/ dependence & loyalty \\
\hline Rapport & intimacy & critical & Loyal \\
\hline Scaffolding/ tutoring & Uncertainty & controversy & betrayal \\
\hline Intervention & Too much independence & Too less critical & Organize \\
\hline $\begin{array}{l}\text { Dialogical skills } \\
\text { strategies }\end{array}$ & Listen and speak out & Debate & Organizing \\
\hline $\begin{array}{l}\text { Learner's } \\
\text { communicative } \\
\text { competence }\end{array}$ & Sharing & Contesting & $\begin{array}{l}\text { Learners in cohesive just use } \\
\text { knowledge as a tool to } \\
\text { organize knowledge. }\end{array}$ \\
\hline $\begin{array}{l}\text { Learner's } \\
\text { knowledge }\end{array}$ & $\begin{array}{l}\text { Learners in collaborative context } \\
\text { tend to share existing knowledge to } \\
\text { generate potential knowledge; }\end{array}$ & $\begin{array}{l}\text { Learners in competitive context } \\
\text { are inclined to build knowledge, }\end{array}$ \\
\hline
\end{tabular}

\section{Can Teachers' Role and Tutoring Be Totally Left out or Ignored?}

Alexander $(2008,117)$ argues that teacher-student talk 'still remains closer to recitation than to dialogue', so there is 
a 'need to be honest' about the issues being met in attempting to facilitate a culture of dialogical teaching. Actually, teachers play a necessary role as tutor, a scaffold-provider who promotes the ongoing dialogical interaction and do not obstruct or intervene in the learner's intention and participation in dialogues. Teachers should be sensitive to learners' enthusiasm and initiatives, and employ talk to provide them with the support of continuity and ensuring reciprocity (Myhill, 2006). In order to learn from each other, learners benefit from teacher-guided participation (Rogoff, 2008). Facing the phenomenon of many voices countering and responding to each other, teachers should build on learners' contributions (Bakhtin, 1986) or even show gratitude to learners due to knowledge building through these voices. Recent research has been inspired by Bakhtin's dialogic theories on teachers' role in "developing awareness in students an ability to question and to be able to think for themselves" (Wegerif, 2010). Mercer and Littleton (2007) argue that, "for a student to learn and a teacher to teach, talk and joint activity must be used by them to negotiate and establish a shared communicative space" (p.21). When a communicative space is built, through further dialogue teachers are able to extend students' strategic thinking and content knowledge (Gibbons, 2003; Renshaw \& Brown, 2007). Transformative learning (Harris, et al, 2008), which puts emphasis on affective, cognitive, and behavioral change, relies strongly upon the responsibility of the teacher/tutor as a role model whose critical reflection and personal experiences lead to an environment conductive to learner transformation (Ya-ting Carolyn Yang, 2012). Interactional patterns where the teacher plays a role as an 'enabler of talk for learning and thinking' rather than an 'orchestrator of classroom talk' (Wells \& Arauz, 2006; Myhill, 2006) are keys to supporting talk that promotes students' understanding and meaningconstruction. In some sense, the teacher should act as a guide and community organizer (LeAnn G.Putney, 2011) who serves as the community enabler instead of as the implementer of action plans (Bandura, 1997).

\section{Try to Find Provisional Problems and Possible Solutions}

Given that, the featured contexts seem to motivate or delay interactive dialogues in knowledge acquisition in group settings. For example, in a competitive environment where learners are increasingly expected to bear the cost of time and energy wasted in a contest, learners need some support or intervention from others. Apart from this, any kind of talk or dialogues should be not only used by learners to acquire knowledge, but to use and create knowledge.

Strategic knowledge and procedural knowledge should be focused on in dialogical interaction, specifically, how to organize dialogues to acquire knowledge and in what ways to think and to perceive in this process go hand in hand with declarative knowledge. The facilitation of exploratory talk (Mercer \& Littleton, 2007) has promoted the individual reasoning and argumentation and development of skills in groups with effect. In addition, an emphasis on understanding, providing timely and necessary feedback on learning processes, and associating learning with learners' real lives are crucial to improve their conversational or communicative skills in dialogues (Plowman \& Stephen, 2005).

Intervention efforts are made to promote productive dialogical interactions (Wells \& Arauz, 2006; Mercer \& Littleton, 2007). How is the teacher/tutor to provide timely intervention? In different contexts, intervention means different approaches, that is, the approach which is fit for this context is not suitable for that one. Intervention depends on different times and learners if it is to be ensured to have maximal effect in dialogues. The extent of the teacher's interventions is usually expected to be reduced to a minimum in most time.

How can the teacher/tutor provide necessary scaffoldings in dialogues? Scaffoldings are in flux in the process of interactive learning from the start of group formation where advice and adjustment are given to help learners make decisions to the midst of tasks completion where the manipulability of guidance and knowledge structures are stressed.

As is often the practice in Wuxiang High School, dialogues cover many patterns such as (1) Complementary dialogues through which learners share existing knowledge and remove "knowledge gaps"; (2) Linear dialogues where learners answer questions one by one according to the collective objective or the problem; (3) Tasks-distribution dialogues which are used to organize the tasks; (4) "tutor-tutee" guide dialogues; (5) Interactive "interviewerinterviewee" dialogues; (6) "Paradoxical" debate dialogues. While in dialogues, types of "peer-to-peer" interactive modes are multi-selected, peers' "listen - tell" behaviors are multi-improved, peers' "information exchange" deviations are multi-corrected. In the choice of students' interactive presentation, dialogues are launched to establish the presentation mechanism such as (1) Preview-report dialogues; (2) Problem-presentation dialogues; (3) knowledgeconsolidation dialogues; (4) conclusive dialogues; (5) reflective dialogues. These practices will help researchers and other stakeholders understand how dialogical interaction help learners acquire knowledge well.

\section{CONCLUSION}

The research is to wrestle with questions such as "can dialogical interaction be really in the service of Linguistic knowledge acquisition in group settings?"; "How can it work according to different contexts?". To offer some perspectives to these complex issues, one prospect has been concentrated on - the relationship between dialogical interaction and knowledge acquisition through dialogues and necessary scaffoldings as well as intervention. Within these areas, pedagogical tutoring and dialogues has won many scholars' interest (e.g, Chi et al, 2010, 2011a, 2011b; Murrary \& VanLehn, 2006). However, previous studying in this area has mainly dealt with methods and strategies, or many variables that affect learners' knowledge acquisition in dialogical interactions make it impossible for researchers to predict the degree to which specific operations of dialogical interaction are carried out and what content is addressed. This research puts an emphasis on particular contextual factors of the knowledge-acquiring process in dialogical 
interaction and establishes some relationships between words in dialogues and cognitive influence on knowledge acquisition in the process of dialogical interaction. In broadening the vision of this research, dialogic models are extracted from practice in collaborative, competitive, and cohesive contexts in group settings.

In an effort to provide more perspectives on recent development of dialogical interaction, the predominant theme throughout this paper is that there is a tendency to enable more effective knowledge acquisition through commutative talk especially dialogues and scaffoldings or even intervention in the interactive context. There are limitations to this study. One limitation is that the group settings and their interactions are confined to the situations within the class, and the internal dynamics of students and inner state of learners are not clearly sketched out. Another potential limitation is that the validity of this study remains to be seen in promoting an independent sense of knowledge acquisition, which leaves another question that "drawing on dialogical interaction, how can learners' self-identity promote socialidentity?"

\section{REFERENCES}

[1] Alexander, R. J. (2001). Culture and pedagogy: international comparisons in primary education. Oxford: Blackwell.

[2] Alexander, R. (2004). Toward dialogic teaching: Rethinking classroom talk. Cambridge: Dialogos.

[3] Alexander, R. (2006). Towards dialogue teaching ( $3^{\text {rd }}$ ed.). New York: Dialogos.

[4] Alexander, R. L. (2008). Essays on pedagogy. London: Routledge.

[5] Alexander, R. (2008). Culture, dialogue and learning: Notes on emerging pedagogy. In N. Mercer \& S. Hodgkinson (eds.), Exploring talk in school (pp.91-114). London: Sage.

[6] Apker L. and Eddly S. (2004). Communicating professional identity in medical socialisation: considering the ideological discource of morning report. Qual Health Res, 14,411-29.

[7] Arksey, H. and Knight, P. (1999). Interviewing for Social Scientists. London: Sage.

[8] Aronson, E. and Patnoe, S. (1997). The jigsaw classroom: Building cooperation in the classroom (2 ${ }^{\text {nd }}$ edn). New York: Addison Wesley Longman.

[9] Aronson, E. and Thibodeau, R. (1992). The jigsaw classroom: A cooperative strategy for reducing prejudice. In J. Lynch, C. Modgil and S. Modgil (eds), Cultural diversity in the schools. London: Falmer Press.

[10] Aronson, E. and Yates, S. (1983). Cooperation in the classroom: The impact of the jigsaw method on inter-ethnic relations, classroom performance and self-esteem. In H. Blumberg and P. Hare (eds), Small groups. London: John Wiley \& Sons.

[11] Arjen E. J. and Schwarzin, Lisa. (2012). Fostering organizational sustainability through dialogic interaction. The Learning organization, 19 (1), 11-27.

[12] Bakhtin, M. M. (1986). Speech genres and other late essays. Austin, TX: University of Texas Press.

[13] Bandura, A. (1997). Self-efficacy: The exercise of control. New Tork, NY: W.H. Freeman \& Co.

[14] Barker, S. C., \& MacIntyre, P. D. (2000). The role of gender and immersion in communication and second language orientations. Language Learning, 50, 311-241.

[15] Barnett, R. (2005). Transferring learning from the classroom to the workplace: challenges and implications for educational leadership preparation. Educational Considerations, 32 (2), 9-18.

[16] Bauman, R. (2000). Language, identity, performance. Pragmatics, 10 (1): 1-5.

[17] Bereiter, C., \& Scardamalia, M. (2014). Knowledge building and knowledge creation: one concept, two hills to climb. In S. C. Tan, H. J. So, \& J. Yeo (Eds.), Knowledge creation in education (pp. 35-52). Singapore: Springer.

[18] Bereiter, C., Scardamalia, M., Cassells, C., \& Hewitt, J. (1997). Postmodernism, knowledge-building, and elementary science. Elementary School Journal, 97 (4), 329-340.

[19] Billig, M. (1996). Arguing and thinking: A rhetorical approach to social psychology (2 ${ }^{\text {nd }}$ ed.). Cambridge, England: Cambridge University Press.

[20] Blatchford, P., Kutnick, P., Baines, E., \& Galton, M. (2003). Toward a social pedagogy of classroom group. International Journal of Educational Research, 39, 153-172.

[21] Blatchford, P., Baones, E. Rubie-Davies, C., Bassett, P., Chowne, A. (2006). The effect of new approach to group-work on pupil-pupil and teacher-pupil interaction. Journal of Educational Psychology, 98,750-765.

[22] Bleakley A. (2006). You are who I say you are: the rhetorical construction of identity in the operating theatre. JWorkplace Learn, 17,414-25.

[23] Brewer MB. (2001). The many faces of social identity: implications for political psychology. Pol Psychol, 22, 115-25.

[24] Bronn, P. S. and Bronn, C. (2003). "A reflective stakeholder approach: co-orientation as a basis for communication and learning”, Journal of Communication Management, Vol.7 No. 4, pp.291-303.

[25] Brown, J. S., Collins, A. and Duguid, P. (1989). "Situated Cognition and the Culture of Learning." Educational Researcher, 18 (1).

[26] Bruner, J. (1996). The culture of education. Cambridge, MA: Harvard University Press.

[27] Chen Xiangming. (2003). Group cooperative learning conditions. Tsinghua University Education Research, 24 (2): 11-16.

[28] Chi, M. T. H., Siler, S. A., Jeong, H., Yamauchi, T., \& Hausmann, R. G. (2001). Learning from human tutoring. Cognitive Science, 25(4), 471-533.

[29] Chi, M., VanLehn, K., Litman, D., \&Jordan, P. (2010). Inducing effective pedagogical strategies using learning context features. In P. Debra, A. Konsa \& D. Chin (Eds.), User Modeling, Adaptation and personalization: 18th International Conference. UMAP 2010 (pp.147-158). Heidelberg, Germany: Springer.

[30] Chivonne Algeo. (2014). Exploring Project Knowledge Acquisition and Exchange Through Action Research. Project Management Journal, 45 (3), 46-56.

[31] Chi, M., VanLehn, K., Litman, D., \& Jordan, P. (2011a). An evaluation of pedagogical tutorial tactics for a natural language tutoring system: A reinforcement learning approach. International Journal of Artificial Intelligence in Education, 21, 83-113. 
[32] Chi, M., VanLehn, K., Litman, D., \& Jordan, P. (2011b). Empirically evaluating the application of reinforcement learning to the induction of effective and adaptive pedagogical strategies. User Modeling and User adapted Interaction, 21,137-180.

[33] Chuy, M., Resendes, M., Tarchi, C., Chen, B., Scardamalia, M., \& Bereiter, C. (2011). Ways of contributing to an explanationseeking dialogue in science and history. QWERTY: Journal of Technology and Culture, 6 (2),242-260.

[34] Cooper, D. C. and Schindler, P. S. (2001). Business Research Methods (seventh edition). New York: McGraw-Hill.

[35] Denzin, N. K. (1995). The experiential text and the limits of visual understanding. Educational Theory, 45, 7-18.

[36] Dewar, B., \& Sharp, C. (2006). Using evidence: How action learning can support individual and organizational learning through action research. Educational Action Research, 14(2), 219-237.

[37] Dillenbourg, P. (2002). Over-scripting CSCL: The risks of blending collaborative learning with instructional design. In P. A. Kirschner (Ed.), Three worlds of CSCL. Can we support CSCL? (pp. 61-91). Heerlen: Open Universiteit Nederland.

[38] Edward, R. (2008). Competitive Debate: The Official Guide. Penguin Group, New York.

[39] Ellemers, N. and S. A. Haslam, (2012). "Social Identity Theory". In Handbook of Theories of Social Psychology, Vol.2, Edited by A.M. Van Lange, A. W. Kruglanski, and E. T. Higgins. Thousand Oaks, CA: Sage.

[40] Gee. J. P. (1999). An introduction to discourse analysis: Theory and Method. London: Routledge.

[41] Gee, J. P. and Green, J. (1998). Discourse analysis, learning and social practice: a methodological study. Review of Research in Education, 23:119-169.

[42] Greeno, J. G. (1997). On claims that answer the wrong questions. Educational Research, 26 (1), 5-17.

[43] Grugeon, E., Hubbard, L., Smith, C. \& Dawes, L. (2001). Teaching, speaking and listening in the primary school (2nd edn). London, David Fulton.

[44] Gibbons, P. (2003). Mediating language learning: teacher interactions with ESL student in a content-based classroom. TESOL Quarterly, 37 (2), 247-273.

[45] Graesser, A. C., Person, N. K., \& Magliano, J. P. (1995). Collaborative dialogue patterns in naturalistic one-on-one tutoring. Applied Cognitive Psychology,9,495-522.Doi:10.1002/acp.230090604.

[46] Grossen, M. (2010). Interaction Analysis and Psychology: A Dialogue Perspective. Integrative Psychological and Behavioral Science, 44, 1-22. Doi: 10.1007/s12124-009-9108-9.

[47] Gunnlaugson, O. (2007). "Shedding light on the underlying forms of transformative learning theory: introducing three distinct categories of consciousness", Journal of Transformative Education, Vol.5 No.2, pp. 134.51.

[48] Harris, S., Lowery-Moore, H., \& Farrow, V. (2008). Extending transfer of learning theory to transformative learning theory: a model for promoting teacher leadership. Theory into Practice, 46 (4), 318-326.

[49] Heymann, F. and Wales, A. E. J. (2002). "Cultivating conflict and pluralism through dialogical deconstruction", in Leeuwis, C. and Pyburn, R. (Eds), Wheelbarrows Full of Frogs: Social Learning in Resource Management, Van Gorcum, Assen, pp.123-41.

[50] Hood, P. (2007). What do we teachers need to know to enhance our creativity? A report on a pilot project into primary school students' perceptions of their identities as learners. Education, 36(2), 139-151.

[51] Hurst, D. K. (1995). Crisis \& Renewal: Meeting the Challenge of Organizational Change, Harvard University Press, Boston, MA.

[52] Huber, G. P. (1991). Organizational learning: the contributing processes and the literatures. Organization Science, 2, 88-115.

[53] Hycner, R. (1993). Between Person and Person, The Grestalt Journal Press Inc, Gouldsboro, ME.

[54] Hymes, D. (1971). Competence and performance in linguistic theory. In R. Huxley \& E. Ingram (Eds.), Language acquisition: Models and methods (pp. 3-28). London: Academic Press.

[55] Inkpen, A. C. (1998). Learning and knowledge acquisition through international strategic alliances. Academy of Management Executive, 12(4), 69-80.

[56] Kepner, J. (2003). The embodied field, British Gestalt Journal, Vol.12 No. 1, pp.6-14.

[57] Koschmann, T. (1999). Toward a dialogica theory of learning: Bakhtin's contribution to understanding learning in settings of collaboration. In C. Hoadley \& Roscheller (Eds.), Proceedings of the Computer Supported Collaborative Learning (CSCL), Dec.12-15, Stanford University. Mahwah, NJ: Erlbaum.

[58] Kuhn, D. (1992). Thinking as argument. Harvard Educational Review, 62, 155-178.

[59] Kuhn, D., \& Udell, W. (2003). The development of argument skills. Child development, 74(5), 1245-1260.

[60] Lennox, Sandra. (2013). Interactive Read-Alouds-An Avenue for Enhancing Children's Language for Thinking and Understanding: A Review of Recent Research. Early Childhood Educ J, 41,381-389.

[61] LeAnn G. Putney., \& Suzanne H. Broughton. (2011). Developing collective Classroom Efficacy: The Teacher's role as community organizer. Journal of Teacher Education, 62(1), 93-105.

[62] Lethbridge, T. C. (1991). A model for informality in knowledge representation and acquisition. Workshop on Informal Computing.

[63] Linell, P. (1998). Approaching dialogue: Talk, interaction and contexts in dialogical perspective. Amsterdam: John Benjamins.

[64] Linell, P. (2009). Rethinking language, mind, and world dialogically: Interactional and contextual theories of human sensemaking. Charlotte, NC: Information Age Publishing.

[65] Lu Haidong. (2005). School Education Psychology. Changchun: Northeast Normal University Press.

[66] Lujan, H. L., \& Dicarlo, S. E. (2006). Too much teaching, not enough learning: what is the solution?. Ajp Advances in Physiology Education, 30(1), 17-22.

[67] Marjan Laal. (2013). Collaborative learning; elements. Social and Behavioral Sciences, 83,814-818.

[68] Ma Hongliang. (2003). Cooperative learning connotation, elements and significance. Foreign Educational Research, 30 (5): 16-19.

[69] M. Beatrice Ligorio. (2010). Dialogical Relationship between Identity and Learning. Culture \& Psychology, 16 (1): $93-107$. Doi:10.1177/1354067X09353206.

[70] Martin, D. (2005). "Dialogue and spirituality", in Banathy, B. And Jenlink, P.M. (Eds), Dialogue as a Means of Collective Communication, Kluwer Academic/ Plenum Press, New York, NY, pp.123-36. 
[71] Means, M. L., \& Voss, J. F. (1996). Who reasons well? Two studies of informal reasoning among children of different grade, ability, and knowledge levels. Cognition and Instruction, 14, 139-179.

[72] Mercer, N., \& Littleton, K. (2007). Dialogue and the development of children's thinking: A sociocultural approach. London: Routledge.

[73] Mezirow, J. (2000). Learning to think like an adult: Core concepts of transformation theory. In J. Mezirow \& Associates (eds.), Learning as transformation (pp.3-33). San Francisco, CA: Jossey-Bass.

[74] Mercer, N. \& Littleton, K. (2007). Dialogue and the development of children's thinking: A socio-cultural approach. London: Routledge.

[75] Mills, G. E. (2003). Action research: A guide for the teacher researcher. Upper Saddle River: Merrill.

[76] Mishler, E. G. (1991). Representing discourse: The rhetoric of transcription. Journal of Narrative and Life History, 1, $255-280$.

[77] Moyles, J. (2002). Observation as a research tool. In M. Coleman, and A. J. Briggs (eds) Research Methods in Educational Leadership. London: Paul Chapman, 172-91.

[78] Munsell, Paul and Tomas Carr. (1981). Monitoring the Monitor: A Review of Second Language Acquisition and Second Language Learning." Language Learning, 31:493-502.

[79] Myhill, D. (2006). Talk, talk, talk: Teaching and learning in whole class discourse. Research Papers in Education, 21(1), 19-41.

[80] Ochs, E. (1996). Linguistic resources for socializing humanity. In J. Gumperz and S. Levinson (eds), Rethinking linguistic relativity (pp. 407-37). Cambridge: Cambridge University Press.

[81] Ostrom TM, Carpenter SL, Sedikides C, Li F. (1993). Differential processing of in-group and out-group information. J Pers Soc Psychol, 64, 21-34.

[82] Pontecorvo, C., \& Sterponi, L. (2002). Learning to argue and reason through discourse in educational settings. In: G. Wells \& Claxton (Eds.), Learning for life in the 21th century (pp. 127-140). Oxford: Balckwell.

[83] Postmes T, Branscombe NR. (2010). Sources of Social identity. In: Postmes T. Branscombe NR, eds. Rediscovering Social Identity. Hove: Psychology press, 1-12.

[84] Ren Kai, Tim Simo. (2013). How to stimulate students to learn energy. Course, Textbook, Teaching Method, 33 (2): 29-35.

[85] Renshaw, P., \& Brown, R. A. (2007). Formats of classroom talk for integrating everyday and specific discourse: replacement, interweaving, contextual privileging, and pastiche. Language and Education, 21 (6), 531-549.

[86] Riach, K. (2009). Exploring Participant-cantered Reflexivity in the Research Interview. Sociology, 43 (2), 356-370.

[87] Robson, C. (2002). Real World Research (second edition). Oxford: Blackwell.

[88] Rogoff, B. (2008). Observing sociocultural activity on three planes: Participatory appropriation, guided participation and apprenticeship. In P. Murphy, K. Hall, \& J. Soler (Eds.), Pedagogy and practice: culture and identities ( pp.58-74). Los Angeles, London, New Delhi and Singapore: Sage.

[89] Roper, J., Zorn, T. and Weaver, C.K. (2004). "The communicative properties of science and technology dialogue", Ministry of Research Science and Technology, Wellington, available via: www. Morst.govt.nz/publications/a-z/s/science-dialogue-2004/ (accessed July 30, 2011).

[90] Russell, B. H., \& Gery, R. W. (2010). Analyzing Qualitative Data: Systematic Approaches. Los Angeles. London: Sage.

[91] Salonen, P., Vauras, M., \& Efklides, A. (2005). Social interaction: What can it tell us about metacognition and coregulation in learning? European Psychologist, 10, 199-208.

[92] Savignon, Sandra J. (1983). Communicative Competence: Theory and Classroom Practice. Reading, MA: Addison-Wesley Publishing Company.

[93] Scharmer, C. O. (2009). Theory U: Leading from the Future as it Emerges - The Social Technology of Presencing, Berrettkpehler, San Francisco, CA.

[94] Schreiber, T. (2004). Diskursanalyse som metode til identificering af kollektive informationsbehov, Bibioteksarbeide, Vol.70, pp. 47-62.

[95] Seng, S. C., \& Liu, H.Q. (2005). Cooperative Classroom: Energetic Learning. Shanghai: East China Normal University Press.

[96] Simon B. (1992). The perception of in-group and out-group homogeneity: reintroducing the intergroup context. Eur Rev Soc Psychol, 3, 1-30.

[97] Simpson, M. and Tuson, J. (2003). Using Observations in Small-Scale Research: A Beginner's Guide (revised edition). Glasgow: University of Glasgow, the SCRE Centre.

[98] Singh, T. K. R., \& Mohammed, A. R. (2012). Secondary students' perspectives on the use of the Interactive. Whiteboard for teaching and learning of Science in Malaysia. Journal of Education and Practice, 3(7), 9-15.

[99] Slavin, R. E. (1980). Cooperative learning in teams: State of the art. Educational Psychologist, 15:93-111.

[100] Slavin, R. E. (1989/1990). Research on cooperative learning: Consensus and controversy. Educational Leadership, 47 (4): $52-5$

[101] Slavin, R. E. (1995). Cooperative learning: Theory, research and practice ( $2^{\text {nd }}$ edn). Boston: Allyn \& Bacon.

[102] Swan, J., Newell, S., Scarebrough, H.,\& Hislop, D. (1999). Knowledge management and innovation: Networks and networking. Journal of Knowledge Management, 3 (4), 262-275.

[103] Tajfel, H., J. C. Turner. (1979). An integrative theory of group conflict. W. G. Austin, S. Worchel, eds. The Social Psychology of Intergroup Relations. Brooks/Cole, Monterey, CA, 33-47.

[104] Talja, S., Tuominen, K. and Savolainen, R. (2005). 'Isms' in information science: constructivism, collectivism and constructionism, Journal of Documentation, Vol. 61 No. 1, pp.79-101.

[105] Tuominen, K. Talja, S. and Savolainen, R. (2003). Multiperspective digital libraries. The implication of constructionism for the development of digital libraries, Journal of the American society for Information Science and Technology, Vol. 54, pp. 561-9.

[106] Turner JC. (1985). Social categorisation and the self-concept: a social cognitive theory of group behaviour. In: Lawler EJ. ed. Advances in Group Processes: Theory and Research. Greenwich, CT: JAI Press, 77-122.

[107] Van de Sande, C., \& Greeno, J. G. (2010). A framing of instructional explanation: Let us explain with you. In M.K. Stein \& L. Kucan(eds.), Instructional explanations in the disciplines (pp.69-82).New York, NY: Springer.

[108] Van Gorder, A.C. (2007). "Pedagogy for the children of the oppressors: liberative education for social justice among the world's privileged", Journal of Transformative Education, Vol. 5 No. 1, pp.8-32. 
[109] Van Dijk, T. A. (1998). Ideology: A multidisciplinary approach. London: Sage Publications.

[110] Von Krogh, G., Ichijo, K., \& Nonaka, I. (2000). Enabling knowledge creation: Unlocking the mystery of tacit knowledge. New York: Oxford University Press.

[111] Wales, A. E. J., Van der Hoeven, N. And Blankern, H. (2009). The Acoustics of Social Learning: Designing Learning Processes that Contribute to a More Sustainable world, Wageningen Academic Publishers, Wageningen.

[112] Watts, M. and Ebbutt, D. (1987). More than the sum of the parts: research methods in group interviewing. British Educational Research Journal, 13 (1), 25-34.

[113] Wenger, E. (1998). Communities of practice: Learning, meaning, and identity. Cambridge: Cambridge University Press.

[114] Wegerif, R. (2010). Dialogue and teaching thinking with technology: Opening, expanding and deepening the 'inter-face'. In K. Littleton \& C. Howe (Eds.), Educational dialogues: Understanding and promoting productive interaction (pp.338-357). London and New York: Routledge.

[115] Wegerif, R., \& Mercer, N. (2000). Language for thinking: a study of children solving reasoning test problems together. In H. Cowie \& G.van der Aalsvort (Eds.), Social Interaction in Learning and Instruction (pp. 179-192). Oxford: Pergamon.

[116] Wells, G., \& Arauz, R. (2006). Dialogue in the classroom. Journal of the Learning Sciences, 15 (3), 379-428.

[117] Wilhelmson, L. (2006). "Dialogue meeting as nonformal adult education in municipal context", Journal of Transformative Education, Vol. 4, pp.243-56.

[118] Wilder DA. (1990). Some determinants of the persuasive power of in-groups and out-groups: organisation of information and attribution of independence. J Pers Soc Psychol, 59, 1202-12.

[119] Ya-Ting Carolyn Yang. (2012). Cultivating critical thinkers: Exploring transfer of learning from pre-service teacher training to classroom practice. Teaching and Teacher Education, 28, 1116-1130.

[120] Yashima, T., Zenuk-Nishide, L., \& Shimizu, K. (2004). The influence of attitudes and affect on willingness to communicate and second language communication. Language Learning, 54, 119-152.

[121] Yorks, L. and Kasl, E. (2006). I know more than I can say: a taxonomy for using expressive ways of knowing to foster transformative learning, Journal of Transformative Education, Vol. 4, pp. 43-64.

Huanjie Wang was born in Ningbo, China in 1982. He has been a Professional Doctorate student in Education in the University of Nottingham School of Education and English, China since 2016.

With Teacher of Senior Professional Title, He is currently the deputy director of the Teacher Development Department of Wu Xiang High School in Ningbo. His main research interests include Chinese-English cross-language, language and thinking, SinoForeign cultural differences, student dialogue and knowledge, and language acquisition mechanism.

Dr. Wang has published more than 50 articles in various journals such as People's Education, China Education Journal, and English Teaching and Research in Primary and Secondary Schools and so on. 